Northup points out, but at least it is less harmful than most therapeutic agents used today.

I would also like to comment on Dr Pecora's article "Factors influencing osteopathic physicians' decisions to enroll in allopathic residency programs" (JAOA 1990;90:527-533). I agree that the quality of allopathic residency programs is one major reason osteopathic physicians choose to enroll in them. Various individuals-including my two sons who are osteopathic physicians-have brought this fact to my attention over the years.

Using the talents of allopathictrained osteopathic physicians is one method to upgrade the quality of our residency programs. However, those persons in positions of power in the American Osteopathic Association have managed, for years, to alienate these physicians by enacting policies that lack insight or imagination. It is time for these individuals to grow up and join the real world.

FRANCIS E. DAVIS, DO

Daytona Beach, Fla

\section{'General practice' requires changing}

\section{To the Editor:}

I am writing to comment on recent discussions regarding the title of "general practice"(JAOA $1990 ; 90: 479)$. Now is the time for both the American Osteopathic Association and the American College of General Practitioners in Osteopathic Medicine and Surgery (ACGP) to rid themselves of this archaic designation. It no longer reflects the training and expertise of these practitioners. The "Rose is a rose" theory may hold true for flowers; however, the outdated term of "general practice" could well be interpreted as a field of medicine that requires less skill than the specialty of "family medicine."

There can be no argument that since its inception, osteopathic medicine has trained its students in and promoted the concept of family medicine, as exemplified in our motto "Health for the Whole Family." What reason could exist that would cause the profession to adhere to such an inappropriate title? Isn't it time for our "general practitioners" to have a modern title that is better accepted and aptly reflects their skills and training?

There is no doubt in my mind that the term "general practice" should be dropped in favor of the more appropriate "family medicine" designation.

DARRYLL W. BARKSDALE, DO Biloxi, Miss

(Editor's note: Dr Barksdale is certified in General Practice by the American Osteopathic Board of General Practice:)

\section{Need for documenting OMT}

\section{To the Editor:}

It's about time we osteopathic physicians responded to the ongoing need for documenting the things we do in the office, namely osteopathic manipulative treatment (OMT). In his article, "Quality assurance monitoring of osteopathic manipulative treatment" (JAOA 1990;90:427-434), Dr Koss presents another compelling reason for documentation-quality assurance.

With fine clarity, Dr Koss describes the bureaucratic balancing act physicians serving the armed forces must undertake. The threat of disciplinary action has catalyzed medical management personnel in the armed forces to take strong measures to protect their clientele-and themselves. These protective measures predictably have taken physicians away from their doctoring, thus intensifying already crippling medical service shortages.

It is difficult to see how one can think of OMT as dangerous when physicians practicing general medicine are faced with a $36 \%$ rate of adverse reactions to drugs or other procedures among hospitalized patients.

Clearly, the literature reflects that osteopathic manipulation of the upper cervical area differs from that performed by chiropractors as a group. Is this because osteopathic medical colleges teach students that high-velocity technique to the high cervical area is performed only with the region in partial-never fullextension? Perhaps this is why clinical reports are virtually devoid of DO-caused damage in the upper cervical area. Maybe this difference accounts for the fact that osteopathic physicians practicing manipulative medicine exclusively traditionally have the (continued on page 766) 